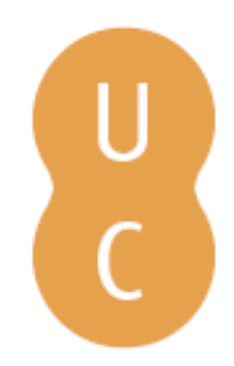

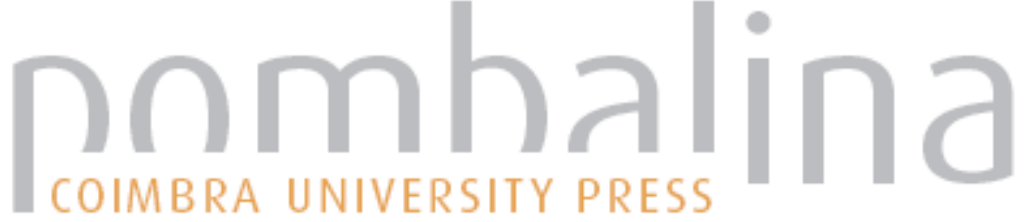

\section{La medicina en el México colonial}

Autor(es): $\quad$ Padilla, Analicia Hinojosa

Publicado por: Imprensa da Universidade de Coimbra

URL

persistente: $\quad$ URI:http://hdl.handle.net/10316.2/32381

DOI: $\quad$ DOI:http://dx.doi.org/10.14195/978-989-26-0469-5_8

Accessed : $\quad$ 26-Apr-2023 08:09:13

A navegação consulta e descarregamento dos títulos inseridos nas Bibliotecas Digitais UC Digitalis, UC Pombalina e UC Impactum, pressupõem a aceitação plena e sem reservas dos Termos e Condições de Uso destas Bibliotecas Digitais, disponíveis em https://digitalis.uc.pt/pt-pt/termos.

Conforme exposto nos referidos Termos e Condições de Uso, o descarregamento de títulos de acesso restrito requer uma licença válida de autorização devendo o utilizador aceder ao(s) documento(s) a partir de um endereço de IP da instituição detentora da supramencionada licença.

Ao utilizador é apenas permitido o descarregamento para uso pessoal, pelo que o emprego do(s) título(s) descarregado(s) para outro fim, designadamente comercial, carece de autorização do respetivo autor ou editor da obra.

Na medida em que todas as obras da UC Digitalis se encontram protegidas pelo Código do Direito de Autor e Direitos Conexos e demais legislação aplicável, toda a cópia, parcial ou total, deste documento, nos casos em que é legalmente admitida, deverá conter ou fazer-se acompanhar por este aviso.

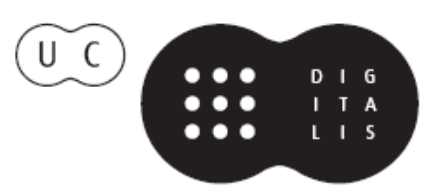


Ana Leunar Pereira João Rui Pita

[ Coordenaçä̃ ]
Rotas da Natureza

Cientistas

Viagens

Expedifgũes

Instituip̧ües

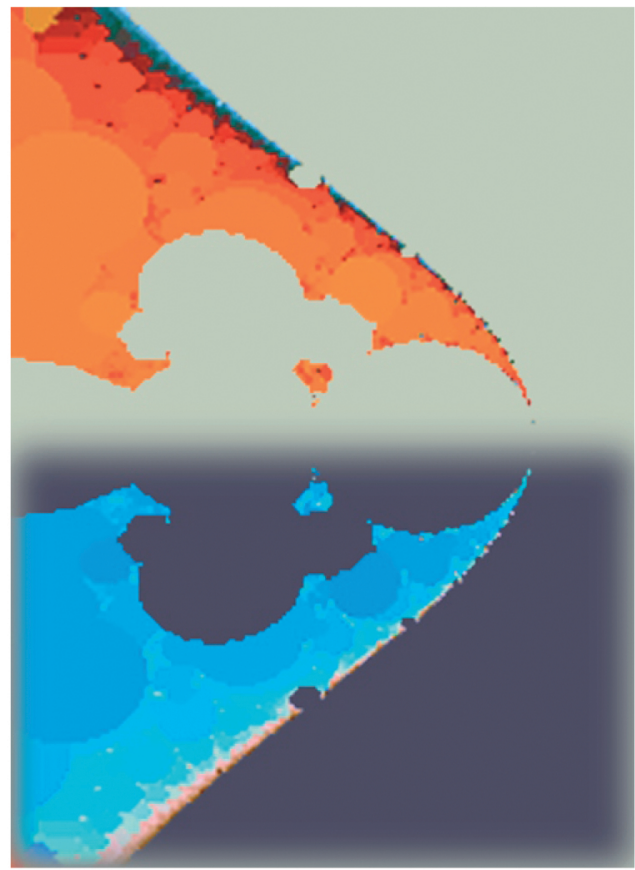




\section{Coordenaçáo Científica da Colecção Ciências e Culturas}

João Rui Pita e Ana Leonor Pereira

Os originais enviados são sujeitos a apreciação científica por referees

\section{Coordenação Editorial}

Maria João Padez Ferreira de Castro

\section{Edição}

Imprensa da Universidade de Coimbra

Email:impresauc@ci.uc.pt

URL: http://www.imp.uc.pt • Normas de publicação de colecçôes

\section{Design}

António Barros

Pré-Impressáo

António Resende

Imprensa da Universidade de Coimbra

\section{Capa}

António Barros, com imagem de E. M. de Melo e Castro, 2003 [Fractal original gerado no Fractint com tratamento no Photoshop 7.0]; Cortesia: António Barros

Impressão e Acabamento

SerSilito • Maia

\section{ISBN}

978-989-8074-12-6

\section{Depósito Legal}

Obra publicada com a colaboraçáo de:
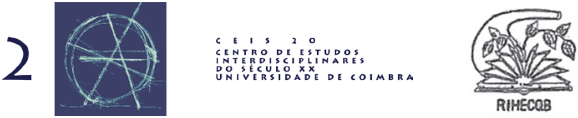

Obra publicada com o apoio de:

FCT Fundação para a Ciência e a Tecnologia

MINISTÉRIO DA CIÊNCIA, TECNOLOGIA E ENSINO SUPERTOR Portug

Programa Operacional Ciência, Tecnologia, Inovação do Quadro Comunitário de Apoio III
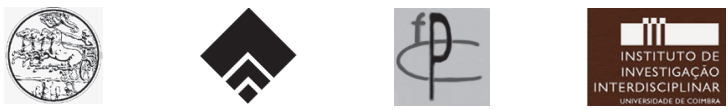

\section{Baxter}

(c) 2006, Imprensa da Universidade de Coimbra 
João Rui Pita

Ana Leonar Pereira

(Courdenação)

Rotas da Natureza

Cientistas

Viagens

Expediçũes

Instituiç̃̃es

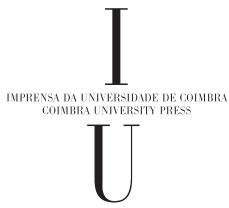

- colmbra 2006 
(Página deixada propositadamente em branco) 


\section{Analicia Hinojosa Padilla}

Titular de la Biblioteca Dr. Nicolás León

de la Facultad de Medicina de la Universidad Nacional Autónoma de México, México

\section{LA MEDicina EN EL MéXico COLONIAL}

México país de vivos colores y sabores de profundas raíces y de grandes contrastes, que ha modificado sensiblemente la pureza de su raza como un resultado de conquistas e invasiones de influencia extranjera, creando nuevos prototipos étnicos poseedores de una maravillosa cultura.

La época de la colonia en México abarca los siglos XVI al XVIII, durante este período histórico nuestro país se formó como una nueva ciudad ya que a la llegada de los españoles México-Tenochtitlan era una isla y los conquistadores tuvieron muchas dificultades para adaptarse al carácter lacustre de la ciudad, entonces emprendieron la sistemática desecación del lago, sin embargo todavía por mucho tiempo después permanecieron algunos canales que la cruzaban y que servían para el transporte de los productos del campo que la abastecían. La ciudad alcanzó hacia fines del siglo XVIII su máximo tamaño y fue considerado como una de las más grandes del continente americano, conservó su diseño original sus calles trazadas en forma de tablero de ajedrez con un centro delimitado por una plaza, rodeada ésta por los edificios donde se asentaron las principales instituciones que gobernaban a la ciudad y al conjunto del territorio novo hispano, el patio virreinal, la catedral., el cabildo y el Parian.

La ciudad de México además de constituirse en el más importante centro de la vida política, social y económica de la Nueva España, fue un núcleo fundamental de transmisión y creación cultural, poco a poco a lo largo del virreinato, se promovieron muy diversas actividades artísticas tales como la arquitectura, escultura y pintura en donde la cantera y el tezontle se unieron para crear el barroco, el churrigueresco y neoclásico en donde la mano de obra india, desde que le fue permitida alguna iniciativa guiada por el arte ancestral, interpretaba los modelos hispánicos de una forma sencilla casi nunca exenta de cierta gracia primitiva, como ejemplo de la arquitectura de ésta época está el Palacio de la Inquisición construido de 17321737 de estilo barroco, por el arquitecto Pedro Arrieta ubicado en la plaza de Santo Domingo, que por poco menos de un siglo fue sede del temido tribunal del Santo Oficio, abolida la Inquisición el inmueble fue fragmentado y dedicado a los más diversos fines, así para el año 1854 este edificio fue comprado por un grupo de profesores médicos que instalaron por 102 años la Escuela Nacional de Medicina.

Durante el período colonial se desarrolló la disciplina y enseñanza de la Medicina como un saber y una práctica, una ciencia y un arte, con la aplicación de valores reli- 
giosos, éticos, culturales, así como con el ejercicio del método científico, la tradición y la experiencia personal del médico. Sabemos que el conocimiento médico se basa en paradigmas que se transforman y que pueden prevalecer en la comunidad científica durante algún tiempo en ocasiones muy largo tal es el caso de la teoría preconizada por Hipócrates y Galeno, quienes concibieron la enfermedad cono un desequilibrio de humores, tesis vigente durante 15 centurias, hasta que Paracelso en el siglo XVI señaló que la enfermedad tenía un origen local y podía ser causada por agentes que provenían del exterior, aportaciones que se suscitaron una idea ontológica y parasitaria de la enfermedad, un hecho importante que conviene resaltar es que entre las disciplinas del conocimiento que surgieron de las primeras universidades europeas medievales, como la filosofía, el derecho, la teología; la medicina fue la única que desarrolló una conexión sistemática con la ciencia y la tecnología, la medicina recibe de diversas disciplinas un caudal de conocimientos cada vez mayor, con el consiguiente flujo de aportaciones científicas y técnicas que determinan el saber y la práctica del médico.

El encuentro entre las dos culturas afectó grandemente el saber de la medicina medieval por parte de los españoles y el conocimiento de los indígenas en la Nueva España, creándose una nueva medicina transformada, producto de la mezcla tanto de conocimientos y prácticas, como de visiones diferentes sobre la enfermedad y la salud, la vida y la muerte, en la sociedad azteca convergieron las herencias culturales de la mayor parte de los pueblos del Anáhuac, cuyo análisis puede revelar el estado de la medicina en la época pre- hispánica, entre las ciencias naturales destacaba la botánica, sobre todo en vinculación con la medicina, el suelo y el clima semi-tropical favorecieron la aparición de una gran variedad de especies de flora, Moctezuma II ${ }^{1}$ regalaba a sus súbditos enfermos plantas medicinales que habían hecho cultivar en los jardines reales, 50 años antes de que se creara el jardín botánico de Padua y 100 años antes del de París, la medicina europea recibió un gran aporte con la flora mexicana, medio siglo después de la conquista, el médico particular de Felipe II, el Dr. Francisco Hernández reunió 1200 especies vegetales curativas, a manera de ejemplo se pueden citar algunas plantas de acción medicinal como la jalapa, el guayacan, la zarzaparrilla, el recino, la valeriana, el toloache y otras más ${ }^{2}$.

El herbolario fue considerado el sucesor del brujo y antecesor del médico, el arte de curar se convirtió en un conocimiento empírico y era tara de sacerdotes y hechiceros la lucha contra la enfermedad, con la intercesión ante los dioses o bien conjurando los espíritus del mal. Los aztecas sabían diferenciar las enfermedades, una bronquitis de una tuberculosis pulmonar o del asma, conocían el delirio, la locura y la epilepsia, la indigestión aguda y la dispepsia, los diferentes tipos de diarreas y las disenterías, el reumatismo y probablemente la gota, confundieron las enfermedades infecciosas a las

\footnotetext{
${ }^{1}$ Noven o tlatoani o rey de México Tenochtitlan hijo de Azayacatl.

2 Jalapa, planta trepadora, con dos o tres tallos herbáceos volubles y delgados se como purgante. Zarzaparrilla, planta trepadora inerme o con pocos espinos provista de rizomas delgados, hojas ovaladas de 10 a 12 cms. de largo; se usa como estimulante sudorífico. Durante mucho tiempo gozó de fama como remedio para la sífilis. Recino o higuerilla, con aspecto de una garrapata. Valeriana, planta herbácea provista de raíz gruesa con flores blancas, Su uso es para los nervios con propiedades antiespamódicas. Toloache pasee hojas de mal olor con flores de color violáceo se usa como narcótico o antiespamódico, puede en grandes dosis ser veneno, Árnica, plata herbácea, vellosa, perenne de unos $50 \mathrm{cms}$. Su uso es para las contusiones.
} 
que dieron el nombre genético de "calenturas», distinguieron el tifo (matlazahuatl) y la fiebre del paludismo (viptlatica), diferenciaron enfermedades de la piel como el cloasma, la sarna, la tiña y el mal de pinto, atribuían a ciertos agentes exteriores como el frío, el viento y la humedad los estados catarrales y el mal del reumatismo, en algunas epidemias llevaban a cabo el aislamiento de los enfermos, entre sus recursos terapéuticos tenían masajes, baño termal (temazcalli) dietas, fricciones, purgas, lavativas así como la sangría, aplicaban también vendajes y férulas para inmovilizar miembros, abrieron abscesos con bisturís de obsidiana, para que saliera el pus y después cocían con cabello en vez de hilo, en algunas excavaciones de Monte Albán fueron encontrados cráneos en los cuales se practicó la trepanación, como Noven o tlatoani o rey de México Tenochtitlan hijo de Azayacatl como Anestesia ocupaban el toloache que los embriagaba, el peyote, así como alguna clase de hongos. Fray Bernardino de Sahagún investigó y reconoció la eficiencia del conocimiento médico de los antiguos mexicanos de igual forma el Dr. Francisco Hernández a fines del siglo XVI.

Ambas culturas tenían su religión y sus creencias y sin embargo tanto los nativos como los españoles rodeaban a la medicina dentro de un campo místico y de autoritarismo y diferían en el concepto del mal, que para los cristiano el demonio es la causa y para los aborígenes eran los mismos dioses quienes participaban de lo bueno y de lo malo, esto es de lo humano como sucede dentro de la mitología griega, así por ejemplo el Dios Tlaloc conocido como el Dios de la lluvia ayuda a la germinación, pero también provoca a su vez las dolencias vinculadas con el frío y con el agua, por otra parte las creencias de los españoles basadas en una concepción medieval religiosa del mundo y de la enfermedad, introdujeron la idea del maleficio, o sea la fuerza mística que pueden provocar la enfermedad conocida como el mal de ojo que tuvo en Santo Tomás a su mayor intérprete, así para los primeros habitantes de la Colonia se generalizó la idea de que las epidemias eran provocadas por un castigo de Dios, por lo que una enfermedad en específico se ligaba a un santo que la podía curar, como por ejemplo a San Basilio se le pedía curara todos aquellos padecimientos relacionados al pulmón y la garganta, a Santa Apolonia sobre las dolencias de los dientes, a San Erasmo se le pedía que mitigara las enfermedades del abdomen.

La aplicación y la educación médica durante la época colonial fueron reguladas por el Protomedicato que observaba rigurosamente la normatividad, producto de los lineamientos recibidos de España, la medicina que se ejercía en la época de la colonia en la Nueva España sin lugar a dudas fue de carácter mixto ya que los españoles criollos y algunos mestizos recurrían a los pocos médicos españoles y los indígenas recurrían a los médicos autóctonos, sin embargo, los que practicaban la medicina ya presentaban cambios culturales de mutua influencia, el surgimiento de las enormes epidemias de viruela, sarampión producto del gran intercambio de genes y antígenos provocaron la creación de hospitales y nos refiere Sahagún «En esta Nueva España murió la mayor parte de la gente que en ella había». En 1520 la viruela (cocoliztli), 1530 el sarampión (topiton zahuatl), la del tifo o tobardillo. Durante el siglo XVI fueron abiertos en la capital unos 10 hospitales y en la provincia más de 20 .

Durante los dos siglos y medio que duró la enseñanza medieval, médicos famosos y hombres orientados al estudio de diversas disciplinas dejaron constancia a través de su obra escrita, la primera que se imprimió en el Nuevo Mundo fue la de Opera Medicinalis del Dr. Francisco Bravo impresa por vez primera en México en 1570. La 
Opera Medicinalis contiene descripciones clínicas, doctrinas médicas, epidemiología, enfermedades infecciosas, dieta y materia médica, que muestra en forma excelente a través de sus grabados y contenidos lo europeo adaptado a la nueva sociedad colonial, el impresor de la obra médica fue Pedro Ocharte, familiar del primer impresor conocido en el mundo Juan Pablos, y el grabador de la obra fue Juan Ortíz. No cabe duda que la Opera Medicinalis introduce en América un gran debate entre los problemas médicos contemporáneos en Europa provocando discusión y juicio, el autor realiza textos en griego provenientes de Galeno de sus propias observaciones clínicas, el mérito de Bravo es la realización de sus descripciones sobre la anatomía y el problema de las enfermedades venéreas y la identificación de lo verdadero y de lo falso sobre la zarzaparrilla.

El primer tratado sobre cirugía fue el libro titulado: Suma y Recopilación de Cirugía con un arte para sangrar muy útil y provechosa de Alonso López de Hinojosa también conocido Hinojosos o bien como se señala en la portada del libro Alonso López natural de los Inojosos, tiene en la portada un grabado en donde aparecen dos frailes uno mostrando un libro abierto al otro enseñándole algún texto en particular, el otro fraile lleva un libro cerrado bajo el brazo y en alto con la mano sostiene una lámpara que da la luz, el título completo de la obra que aparece en la portada, muestra en cada renglón diferente tipografía, así como el nombre del autor haciendo referencia que era cirujano y enfermero del Hospital de S. Joseph de los Indios de la Ciudad de México, dedicado al ilustre S. Don P. Moya de Contreras arzobispo de México, impreso por Antonio Ricardo 1578, al inicio de la obra están las licencias para la publicación de la misma por Don Martín Enríquez quien la realizó por mandato de su excelencia Joan de Cuevas, Don Pedro Mora de Contreras por mandato de su señoría ilustrísimo Martín Ochoa, así como las de Fray Agustín Farfán, el Dr. Francisco Bravo, Bartolomé de Argumedo, el protomédico Dr. De la Fuente, en la dedicatoria, el autor manifiesta el amor hacia los indios y la posibilidad de transmitir su experiencia al fundir la medicina tradicional europea con la indígena mexicana para ayudarlos a vivir sanamente, la obra describe detalladamente la anatomía humana y se cuestiona, sobre las diferentes partes del cuerpo y su relación entre ellas, dice qué remedio utilizar o como proceder en cada caso, al final de la obra presenta una Tabla de Contenido de los diferentes capítulos del libro y termina con dos grabados, uno de San José y el otro de la Virgen María.

El primer médico graduado en México fue el sevillano Agustín Farfán en 1567 y años más tarde se ordena como sacerdote, realizó dos obras que son fundamentales para el estudio de la historia de la Medicina en México, el primer libro es el Tratado Breve de Anatomía y Chirugía y de algunas enfermedades que más comúnmente suelen haber en la Nueva España, compuesto por el muy reverendo padre Fray Agustín Farfán, doctor en Medicina y religioso de la orden de San Agustín, dirigido al muy reverendo padre Maestro Fray Martín de Perea provincial de la orden de nuestro padre San Agustín, impreso en México por Antonio Ricardo en 1579, estos datos son tomados de la portada de la obra, la cual también posee un grabado, después de las anuencias para la publicación de la obra otorgadas por Fray Antonio de la Vera Cruz, Fray Martín de Perea el mismo Farfán dedica su obra y le corresponde a Francisco de Solís alabar la obra con la impresión de un bello soneto alusivo a la práctica médica, en esta obra se describe detalladamente las enfermedades como se presentan y como deben de 
atenderse para su curación, casi al final de la obra antes de la Tabla de Contenido existe un grabado del de Fray Agustín Farfán. El segundo libro realizado por Farfán es el Tractado Breve de Medicina el cual se ubica en la biblioteca en la obra Colección Incunables Americanos del siglo XVI volumen X impreso en México en 1592 por Pedro Ocharte en versión facsimilar española, este libro básicamente es un manual para los habitantes de los pueblos alejados, donde no había hospitales ni boticas, en sus obras se observa la influencia indígena, sobre la ciencia médica europea de su tiempo, que muestra la manera en que las creencias mágicas y la ciencia se unían para aliviar las enfermedades.

La obra cumbre del período pre-universitario fue el libro del Dr. Francisco Hernández médico e historiador de su majestad Don Felipe II rey de España y de las Indias y Protomédico de todo el Nuevo Mundo, según se consigna en su obra titulada: Historia Plantarum Novae Hispanie, Hernández después de casi 7 años de arduo trabajo dio fin a la obra que la había sido encomendada, creando 17 volúmenes en los cuales describió con dibujos e índices los productos naturales de la región así como la topografía y antiguedades del Reino Mexicano con un verdadero método y orden sistemático en la descripción de los objetos naturales que coadyuvó a elevar a la Botánica como Ciencia, esta obra se publicó finalmente en el año 1791, después de dos siglos de la expedición que le dio origen, debido a una serie de problemas incluso el incendio del Escorial de 1671 en donde se perdieron varios manuscritos.

Es así como se concluye este recorrido imaginario a través de la historia de la Medicina en la época del virreinato en México a través de los libros que se custodian y difunden en la biblioteca Dr. Nicolás León de la Facultad de Medicina de la Universidad Nacional Autónoma de México.

\section{REFERENCIAS}

Aguilar P., Gilberto. Los Hospitales en México, 1936: ed. La Casa Bayer

Diccionario de aZTequismos. México: ed. Fuente Cultural, 1941. 548 p.

DicCIONARIO DE BIOGRAFÍAS. Barcelona: Nauta, 1997. 1966 p.: il.

FARfÁn, Agustín. Colección de Incunables Americanos. Tratado breve de Medicina. México: 1592. Ediciones Cultura Hispánica. Madrid. 1944

Flores, Francisco de Asís. Historia de la Medicina en México. México: Secretaría de Fomento, 1886$-1888.3 \mathrm{v}$.

Fray Bernardino de Sahagún. Historia general de las cosas de Nueva España, Ed. Porrúa. ; éxocp. 1969

Guerra, Francisco. El Hospital en Hispanoamérica y Filipinas 1492-1898. Madrid, 1994.

HernándeZ, Francisco. Historia de las plantas de la Nueva España. Imprenta Universitaria México, 1942. 3t.

López de Hinojosa. Suma y Recopilación de Cirugía. México, 1578. (copia)

Martínez, Máximo. Las plantas medicinales en México. México: Botas, 1939. 628 p.

Romero de Terreros. Miscelánea de Arte Colonial. México: 1990. Ediciones Espejo de Obsidiana.

SOMOLinos D’ARDois, Germán. Relación y estudio de los impresos médicos mexicanos redactados y editados desde 1521 a 1618. Capítulo cuarto. Sociedad Mexicana de Historia y Filosofía de la Medicina. México, 1982. 


\section{Colecçãa \\ 2 Ciências e Culturas Caimbra 2006}

